\title{
Depression among elderly patients in a General Hospital setting Lefteris Lykouras
}

\author{
Address: 2nd Department of Psychiatry, Attikon Hospital, Athens University Medical School, Greece \\ from International Society on Brain and Behaviour: 3rd International Congress on Brain and Behaviour \\ Thessaloniki, Greece. 28 November - 2 December 2007 \\ Published: 17 April 2008 \\ Annals of General Psychiatry 2008, 7(Suppl I):S20 doi:I0.II86/1744-859X-7-SI-S20
}

This abstract is available from: http://www.annals-general-psychiatry.com/content/7/SI/S20

(c) 2008 Lykouras; licensee BioMed Central Ltd.

With the overall increase of life expectancy, the population of individuals above the age of 65 has increased. Consequently, there is an increase in the frequency that this old age group is admitted in the General Hospital.

For the elderly patient, hospital admission is an intensely stressful event. Facing a physical illness, the unknown and sometimes faceless environment of the modern hospital and the separation from family and friends disturbs the frail emotional balance that characterizes the elderly patient. This "disturbance" of the physical, psychological and social wellbeing of the elderly is not restored by treating the physical reason for admission alone.

Psychiatric disorders are very common in these patients and depression is the most common. Findings from research worldwide will be presented as well as findings from our own prospective study in Attikon University Hospital.

The detection and treatment of psychiatric disorders in elderly General Hospital patients presents a challenge for the psychiatrist. Some factors hinder this effort. Firstly, the patients might be unable to cooperate because of hearing or sight problems but also because of forgetfulness and problems in concentration. The differential diagnosis especially of depression and its treatment have many difficulties.

All these emphasize the great need for training in old age psychiatry the General Hospital psychiatrists. There is also a great need for the detection of cognitive deficits and depression with easy to use screening tests in order to facilitate the psychiatrist's work. 